\title{
Statistical sustainability of a digital organization
}

\author{
Vladimir I. Ananyin ${ }^{a}$
}

E-mail:v.ananiin@gmail.com

\section{Konstantin V. Zimin ${ }^{\mathrm{b}}$}

E-mail: konst.zimin@gmail.com

\section{Mikhail I. Lugachev ${ }^{\mathrm{e}}$}

E-mail: mlugachev@gmail.com

\section{Rinat D. Gimranov ${ }^{\mathrm{d}}$}

E-mail: gimranov_rd@mail.ru

\footnotetext{
${ }^{a}$ Russian Presidential Academy of National Economy and Public Administration Address: 82 build. 1, Prospect Vernadskogo, Moscow 119571, Russia

${ }^{\mathrm{b}}$ The Russian Union of CIO

Address: 34, Seleznevskaya Street, Moscow 123056, Russia

${ }^{\mathrm{c}}$ Lomonosov Moscow State University

Address: 1 build. 46, GSP-1, Leninskie Gory, Moscow 119991, Russia

${ }^{\mathrm{d}}$ PJSC Surgutneftegaz

Address: 1 block 1, Grigoriya Kukuevitskogo Street, Surgut 628415, Russia
}

\begin{abstract}
An important feature of a digital organization is its ability to change rapidly. For an organization to remain capable of rapid change, it must be on the brink of resilience, since a resilient organization always resists change. The article examines the borderline state of the organization, which is on the verge of its stability and instability. In this state, the organization begins to lose predictability in the details of behavior, but still retains predictability in general. The authors called this borderline state the statistical sustainability of the organization. The phenomenon of statistical sustainability of an organization is very similar to the property of stability of the frequency of mass events and average
\end{abstract}


values described in mathematical statistics by a similar term. To analyze the nature of the statistical sustainability of the organization, the authors used the ideas of strange attractors and modes with sharpening from the theory of complex systems. A strange attractor is an area of the organization's behavior that, outside this area, is an area of stability for the organization, and inside it is an area of complete unpredictability. The theory of complex systems has shown that it is in the regions of strange attractors that the conditions for the variability of systems are created, and the theory of modes with aggravation shows the conditions under which this variability can lead to self-organization, that is, the spontaneous emergence of new structures. This article shows that systematic digitalization objectively leads to the formation of the statistical sustainability of the organization and creates the preconditions for maintaining the organization's ability to make rapid changes. In traditional management, the statistical sustainability of an organization is viewed as a threat and a source of risk. Therefore, in the context of systematic digitalization, traditional approaches to management should be significantly refined.

Key words: digital organization; variability; stability/instability of the organization; exponential organization; self-organization; strange attractor; diversity; scattering; digital transformation; statistical sustainability.

Citation: Ananyin V.I., Zimin K.V., Lugachev M.I., Gimranov R.D. (2021) Statistical sustainability of a digital organization. Business Informatics, vol. 15, no 1, pp. 47-58.

DOI: $10.17323 / 2587-814 X .2021 .1 .47 .58$

\section{Introduction}

I $\mathrm{n}$ the first half of the 2000s, successful startups built on new information technologies appeared in the United States. The business models of these organizations were radically different from the existing ones, as they were built on the sharing of data. Such organizations are called digital. Many digital organizations had an amazing property: their businesses had explosive growth and fit well on an exponential curve. These rapidly growing digital organizations are called exponential organizations [1]. Their phenomenal success in the second half of the 2000s triggered a wave of new digital organizations. The inclusion of global business leaders in this wave has launched a powerful trend in the digital transformation of the largest companies themselves. The wave of the formation of digital organizations acquired a grandiose scale when, in the mid-2010s, many states took a course towards building a digital economy and created powerful incentives for digital transformation in their national enterprises [2-5].

By 2020, a large number of digital organizations and organizations are in the process of digital transformation. The study of the nature of exponential organizations began in the early 2010s, and already in 2014, a monumental work by a team of authors from the University of Singularity on the analysis of the patterns of formation of exponential organizations was published in the United States [1]. In this work, the authors showed that all exponential organizations managed to discover not only new forms of organizational, human and informational capital, but also new forms of their synthesis [6]. The authors also showed that in these organizations, the time for both decision-making and their implementation has been drastically reduced. In 
fact, exponential organizations began to transform towards a real-time enterprise (RTE) [7], in which decisions are made and implemented at the rate of development of emerging management situations. In this case, the organization's business gets powerful competitive advantages in the market due to the fact that it finds a solution faster than others and adapts to new changed conditions.

Leadership is important not only to achieve, but also to be able to keep it. The organization will have a competitive advantage in the market until its competitors or partners adopt similar decision-making practices. Then the speed of changes in market situations will be determined not by the speed of some economic market factors, but by the speed of decisionmaking and changes in competitors or even partners. If suddenly it turns out that our competitors or partners are changing faster than ourselves, then at one point our business loses leadership: for competitors we become an easy target, and for partners - a burden.

Digitalization creates support for making not only short-term and medium-term decisions, but also strategic long-term decisions, when it is necessary to recognize a potential "black swan" [8] and have time to prepare for a meeting with it. This problem is of great concern to all the top executives of companies world leaders. Peter Diamandis, in the preface to the book [1], managed to formulate it succinctly: "Today you are forced to compete not only and not so much with established multinational corporations. Your competitor can be any guy from Silicon Valley or Bandra County in Mumbai who sits in his garage and uses the latest online tools to develop and distribute his innovative products" [1]. There are "black swans" that come without any precursors at all, for example, the global pandemic of the coronavirus COVID-19 in 2020. In this case, the ability to quickly change and adapt to new conditions becomes for business just a matter of life or death.
If quick adaptability, that is, the ability to quickly change and adapt to new conditions, is so important for a business, why are there so few companies capable of doing this? What new quality is lacking in business for information technology to become a driver of its real transformation? In our opinion, this new quality is the instability of the organization. This article is devoted to the analysis of instability of the organization.

\section{The instability of the organization as a threat and an opportunity}

Instability is strongly associated with the crisis of the organization and therefore in management traditionally enjoys a bad reputation. Instability threatens to lose the predictability of the organization's behavior and the loss of its manageability. Management feels threatened by it and fights it with all its might. For risk management and crisis management, instability is a marginal state of the organization, which must either be avoided or quickly eliminate the consequences of the crisis that has broken out in the organization [9-11].

However, volatility can be useful when management wants to make rapid changes in their organization. The more resilient an organization is, the more resistant it will be to change, and the less room there will be for rapid and large-scale change. And this is not someone's malicious intent, but an objective manifestation of the same stability. In order to make such changes, the organization must be brought to the brink of sustainability, when it has not yet completely lost the predictability of its behavior. Those who have mastered this art gain a powerful competitive advantage - a high degree of adaptability and innovation of their business.

As we can see, instability brings not only threats, but also opportunities. This can be well observed in both technical and natural systems. In engineering practice, it is well known that the 
high level of maneuverability of a modern fighter is achieved by the fact that its design is initially based on aerodynamic instability. The predictability of fighter control is provided by the operation of the onboard computer control system, which, based on a mathematical model of the dynamics of the fighter flight in real time, provides the pilot with the predictability of motion control. The fighter's aerodynamic instability gives it a great competitive advantage in maneuverability and air superiority, but it is this instability that also creates great risks for it: the failure of the onboard electronics makes its behavior chaotic and unmanageable. If instability is an opportunity for a fighter, then for a transport or passenger aircraft it is a threat that engineers and pilots are constantly fighting against.

In medical practice, it is known that when transplanting an organ, it is necessary to weaken the patient's immunity. The human immune system is the most important mechanism for ensuring the stability of the body, ensuring its integrity and individuality by recognizing and removing foreign substances and cells. Strong immunity will lead to the rejection of someone else's organ, so the immunity must first be weakened, then allow it to carefully, purposefully accept someone else's organ as its own, and only then-to restore immunity again. During the period of weakening of the immune system, it is very important to protect the body from foreign infections. The engraftment of a foreign organ is a complex process of self-organization of the entire body. Here, the human body itself decides how it will act in such a situation, and doctors can only understand it in time and help it.

In contrast to technical and natural systems, an organization is a social system that consists of people who have their own ideas and history of relationships, their own intentions and expectations, motives and norms of behavior. People in an organization build various kinds of mutual relations, so the organization cannot be reduced to a simple set of people, but repre- sents a certain new quality that manifests itself through the objective properties of the organization as a whole. One of these properties is its stability/instability.

\section{Statistical sustainability of the organization}

The concept of stability / instability of the organization is closest to the field of knowledge about management. In the theory of management [12], the object and the subject of management are traditionally distinguished. In our case, the object of management is an operating organization, and the subject is the head (team of managers) of this organization. The management team manages the organization, that is, influences the organization in a way that allows them to achieve the expected results. Management is always carried out in conditions of disturbances, that is, unexpected (unplanned) deviations from the normal operating conditions of the organization and the management itself. Disturbances can have both an external origin (for example, a change in the organization's operating conditions) and an internal origin (for example, the appearance of internal problems, conflicts, or initiatives). Outrages require special management actions from the management team.

An organization will be considered sustainable if any situation caused by outrage is predictable for the management team, that is, the team has sufficient knowledge and experience both in terms of the development of the situation and in ways to resolve it.

The organization will be considered unsustainable if the development of the situation associated with the outrage is unpredictable for the management team.

Let's consider the stability of an organization on the example of a separate business process of a real industrial company.

In a large industrial company, there is a process of agreement of contracts. Each contract 
has a supervisor who is responsible for developing, approving and monitoring the execution of the contract with a supplier. At the stage of joint development of the contract with the supplier and during the approval process with the company's services, many changes are made to the contract, which often require repeated approval with the supplier and other participants. Despite the fact that the company has developed clear regulations and standards for approval, the movement of most contracts in the process is poorly predictable. This is due to the high level of market volatility, changes in the organization itself, as well as a lot of contradictions between the company's divisions, which give rise to a low level of mutual trust, which results in distrust of the contract supervisor. As a result, the approval of each contract for the curator turns from a "race with clear rules on pre-laid paths" to a "cross-country race with changing rules and landscape."

All participants in the process are generally interested in getting contracts agreed as quickly as possible, but also do not want to take on the additional responsibility associated with the uncertainty of the consequences of the resulting changes. Each time, all the participants somehow manage to agree on the speed of development of the situation. It is interesting that the average time for the approval of contracts for the process has remained stable for several years, but the movement of each contract is difficult to predict.

Naturally, the process of agreeing on contracts is subject to disturbances, both external and internal. As a result, we see signs of both stability and instability.

At the beginning of a contract company, when there are still few contracts and standard contracts prevail, the process becomes stable: the movement of each contract becomes predictable and largely complies with the rules of the process.

Last year, by order of the Director General, another control service was introduced to restore order in the process. As a result, the coordination of the participants in the process was greatly slowed down, the process became unstable and unexpected failures of coordination began. Senior managers were surprised to find that they themselves now had to intervene in the "resolution" of coordination conflicts. After all the participants got used to each other again, the process returned to the old mode and its average indicators again became the same as before.

In the given example, we can observe the evolution of the mode of operation of the process from classical stability, that is, complete predictability, to classical instability, that is, complete unpredictability of the process. It is interesting that between these extremes there is still a regime where the movement of each treaty turns out to be a process that has remained very predictable for several years. This mode of operation of the process will be called "statistical sustainability." The phenomenon of statistical sustainability can often be observed both at the level of individual management situations, projects of operational processes, and at the level of the organization as a whole.

\section{Statistical sustainability and self-organization}

Effects similar to statistical sustainability are also widespread in technical and natural systems and are well described in the theory of complex systems [13-17]. The theory of complex systems describes the behavior of technical and natural systems in the form of dynamic mathematical models, where the behavior of the system is represented as the trajectory of its movement in phase space. The theory identifies special states of a complex system, which are peculiar areas of attraction for all the trajectories of its mathematical model. Such a region of attraction of trajectories in the mathematical model is called an attractor $[13,16]$. In the attractor region, the behavior of the system becomes absolutely predictable. An exam- 
ple of such an attractor is the center of a funnel formed by a vortex of water going into the hole of the sink. The attractor is a property of the system itself and reflects the modes of its stable behavior, regardless of the disturbances that occurred in it.

The theory of complex systems also suggests that under certain conditions, the system may have attractors, which represent a limited set of states of the system (a closed region of the phase space of the system), which has special properties. From the outside to this set of states (the phase domain) trajectories describing the behavior of the system are also attracted, but within this region, the behavior of the system is fundamentally unpredictable. In mathematics, such areas are called "strange attractors" [16]. It is interesting that inside such a strange attractor, the behavior of the system at any given time is unpredictable, but, nevertheless, the behavior of the system on average turns out to be quite predictable.

Strange attractors only appear in systems that are open, that is, through which the flow of energy and information passes, and which are in a state of increased dynamics. Strange attractors have an amazing property: when the conditions of the system's activity change, they can disintegrate, giving rise to chaotic behavior of the entire system, but they can also transform into other strange attractors, and even generate stable structures that are classical attractors. Such generation of stable structures, which occurs not by someone's will, but by virtue of the natural laws of behavior of a complex system, is called self-organization [13-16].

The process of contract negotiation discussed above, which is in a state of statistical sustainability, is surprisingly similar to a strange attractor. The constantly reproducing set of practices for the negotiation of contracts clearly manifests itself as an attractor. And this attractor is strange, because when implementing the agreement of each contract, the participants each time find their own specific solu- tion. In addition to the accepted practices, they include interpersonal relationships and "on a live thread" each time they find unique solutions. At the same time, the process indicators for each contract can be considered random variables, but the average indicators for the process as a whole are quite predictable. In this case, the coordination activity is no longer like a race on pre-laid tracks (process), but rather like cross-country orienteering, and even with changing terrain.

In the theory of complex systems, two fundamental processes are distinguished during the formation of structures $[15,18]$ - the mode that generates an increase in diversity, and the mode that reduces (blurs, disperses) diversity in the system.

The mode that generates the growth of diversity in the system is called the "mode with aggravation" (S-mode). This is the mode of explosive growth of any process parameters, for example, the burning process, which turns into an explosion. The regime with aggravation generates a rapid increase in the variety of structures formed in the system. An analog of a regime with aggravation for an organization can be an avalanche-like increase in internal initiatives or conflicts.

The mode that generates a decrease in diversity in the system is called dispersion or dissipation. This is the mode of erosion, dispersion of structures that have arisen in the system, for example, the extinction of flame due to fading fuel burn-up and the dissipation of the released energy. An analogous mode of reducing diversity in an organization can be the coordination of participants, during which they communicate with each other, share information and knowledge, come to agreements and find common solutions.

According to the theory of complex systems, the dynamics of self-organization is determined by the ratio of these two processes.

The dominance of diversity growth over dispersion. This relationship is called the LS- 
mode. The dispersion is less intense ( $\mathrm{L}-$ lower) than the diversity growth process ( $\mathrm{S}$-mode). An analog of LS-mode in an organization is a situation when the participants are hit by a stream of initiatives and conflicts, which for them becomes less predictable and/or they do not have time to respond in a coordinated manner. Under these conditions, the emerging new structures are extremely unstable: they form quickly and disintegrate quickly.

The dominance of dispersion over the growth of diversity. This relationship is called the HS-mode. The dispersion is more intense $(\mathrm{H}-$ higher) than the diversity growth process (S-mode). An analogue of the HS-mode in an organization is a situation where any initiative among its participants is drowned in agreements, generating resistance to changes in established practices. In HS-mode, the organization exhibits the properties of classical stability.

The parity of dispersion and the growth of diversity is the condition for the formation of strange attractors and the phenomenon that in complex systems is called self-organization. Self-organization is the process of spontaneous ordering, the emergence of spatial, temporal, spatiotemporal, or functional structures, occurring in open nonlinear systems $[15,18,19]$. Self-organization is a concept that expresses the ability of complex systems to organize their internal structure not by someone's will, but by virtue of the objective laws of the evolution of complex systems. In complex systems, the shift of parity towards the regime of diversity growth leads to the formation of many new embryonic structures. The subsequent shift of parity towards dispersion triggers the process of natural selection of the most viable structures from the newly formed embryos.

What are these new structures that are emerging in our process of negotiating contracts, which is in the mode of statistical sustainability? New structures are practices that begin to form as informal individual or collec- tive experiences of participants in the reconciliation process. It begins as intuitive partial solutions, without claims to generalization. Further, if the experience survives (that is, if it is reused), then it can be realized as general knowledge. If this general knowledge proves its value, it can be transformed into rational organizational, methodological, personnel and technical solutions.

In our contract agreeing process, its participants manage to find a solution and agree on the changing terms of agreement. Changes in the process come not only from the outside, but are also generated internally by the unique decisions of the participants themselves. The process of agreeing on each contract becomes difficult to predict, but at the same time, parity is achieved between the processes of generating change (increasing diversity) and coordinating the actions of participants (scattering). Under the conditions of statistical sustainability of the process, the shift of parity towards the LS-mode leads to the appearance of a variety of practices, and the shift of parity towards the HS-mode triggers the natural selection of the most viable practices.

In the statistical sustainability mode, the organization requires a lot of attention and respect from the manager. To the one who begins to understand it, it will "prompt" the possible directions of its development. It is pointless to impose your rational ideas and will on the organization. In this case, intuition begins to play a large role in management, but at the same time, intuitive search must go hand in hand with constant rational analysis. If in a stable state of the organization the manager dictates his will to it, then in crisis management he seeks an alliance with it. For many managers, this can be a worldview shock. "Her Majesty" statistical sustainability never forgives disrespect, inattention and slowness. But for understanding and tact, it can reward "royally": the organization receives a powerful generator of new practices. It is in these situations 
that the effect of self-organization appears, which is the basis of innovations and breakthrough solutions.

\section{Statistical sustainability and digitalization}

In traditional organizations, the basis of the value of the created product was the physical properties of the product itself (for example, the level of consumer quality) or the organization of business activities (for example, just-in-time delivery). In digital organizations, the product becomes digital; its value is based on data. At the same time, the more data and program code associated with a digital product, the more opportunities there are to extract value from it [6]. In this case, the business models of interaction with other organizations become digital, that is, they are already fundamentally based on data. The value chains in which an organization is included along with other digital organizations are also becoming digital. Data becomes the "air" that digital organizations "breathe", and new technologies (for example, big data, the Internet of things, machine learning and artificial intelligence, virtual and augmented reality, blockchain) help them to produce, assimilate and use it to build new forms of business organization.

The systematic use of information and new technologies has a strong impact on the parity of the processes of generating change (increasing diversity) and coordinating the actions of participants (dispersion) (Table 1).

The analysis of the impact of digitalization on the balance of processes of generating changes and coordinating the actions of participants (Table 1) shows that digitalization contributes to the growth of variability and diversity of the organization. At the same time, one of the limiting factors for the growth of variability is the development of coordination processes, that is, the ability of an organization to coordinate its actions in the increasing flow of changes. By increasing variability and diversity, digitali- zation shifts parity towards the LS-mode and makes newly formed practices unviable. They disintegrate, and the organization regains parity in the processes of generating change and coordination. This parity manifests itself as the statistical sustainability of the organization. Let's consider an example from real practice.

In many manufacturing companies, the classic implementation of the logistics supply chain of material and technical resources (MTP) includes the stages of planning the production need for MTP, preparing and executing purchases, transportation, storage, release to production, and use. The computerization of the process is implemented by classical ERP systems based on the MRP II model. Due to the fact that there is a gap between the real state of affairs (delivery, volume of MTR in warehouses, sales) and information in the system, as well as due to delays in the receipt and processing of information in the ERP system, stocks are formed in the logistics chain that dampen both areas of uncertainty and the costs of opportunistic behavior. It is with the help of these dampers that the organization is stable in terms of meeting the production needs for MTR. For each MTR application, key indicators are recorded, which are monitored by management when making decisions. And for the process as a whole, some parameters are fixed - the average duration of the purchase, the permissible amount of insurance stock, etc., which determine the organizational and administrative decisions on the process.

Digital transformation is changing this process both in terms of ensuring the reliability of information and in terms of reducing the costs of opportunistic behavior. In the process of transformation, $100 \%$ marking and automatic (without manual input) tracking of MTR (barcodes or RFID tags, readers) is carried out, the transition to fully robotic warehouses is carried out, electronic document management is provided, inforobots are launched to perform all routine and standard operations. 


\section{The impact of digitalization on the parity of the processes of generating change (increasing diversity) and coordinating the actions of participants (scattering)}

Table 1.

\begin{tabular}{|c|c|c|}
\hline $\begin{array}{l}\text { Changes } \\
\text { related to } \\
\text { digitalization }\end{array}$ & $\begin{array}{l}\text { Offiset of parity to the side } \\
\text { of LS-mode }\end{array}$ & $\begin{array}{l}\text { Offset of parity to the side } \\
\text { of HS-mode }\end{array}$ \\
\hline $\begin{array}{l}\text { Increasing } \\
\text { the depth } \\
\text { and scale } \\
\text { of analytics }\end{array}$ & $\begin{array}{l}\text { Intelligent analytics on big data allows you to see what } \\
\text { you could not see before: new threats and opportunities } \\
\text { are opening up more often, which require an increasingly } \\
\text { complex response. In fact, digitalization opens up a large } \\
\text { number of new potential external and internal disturbances } \\
\text { and increases the speed of their development }\end{array}$ & $\begin{array}{l}\text { The same intelligent analytics allows you to } \\
\text { quickly find a solution that is acceptable to all } \\
\text { participants in a difficult situation. It creates } \\
\text { a unified picture that accelerates the coordination } \\
\text { of participants }\end{array}$ \\
\hline $\begin{array}{l}\text { The growth } \\
\text { of the scale } \\
\text { and depth } \\
\text { of integration }\end{array}$ & $\begin{array}{l}\text { The Information space goes beyond the boundaries of } \\
\text { the digital organization itself and opens up (within the } \\
\text { framework of access rights) to other participants in the } \\
\text { value chains. This increases not only the scale, but also } \\
\text { the depth of information integration. Information links in } \\
\text { the chains become stronger, which leads to the fact that } \\
\text { changes in one organization become common to } \\
\text { organizations of the entire chain. Digital organization } \\
\text { becomes more sensitive to external changes }\end{array}$ & $\begin{array}{l}\text { It is the same integration of the information space } \\
\text { that is the basis for the rapid synchronization of } \\
\text { changes in value chains (value chain orchestration). } \\
\text { Stronger information links in the chains are able } \\
\text { to transmit not only changes, but also options for } \\
\text { synchronizing the efforts of the chain participants }\end{array}$ \\
\hline $\begin{array}{l}\text { Increasing } \\
\text { the number } \\
\text { of participants } \\
\text { in coordination }\end{array}$ & $\begin{array}{l}\text { Value chain management dramatically expands the } \\
\text { number of participants in coordination, which means } \\
\text { that there is a sharp increase in the diversity and } \\
\text { variability of their interests, expectations and intentions }\end{array}$ & $\begin{array}{l}\text { Modern information technologies allow us to increase } \\
\text { the efficiency of coordination: quickly find the } \\
\text { necessary participants and form a working group, } \\
\text { quickly create a working information space and } \\
\text { organize group work, attract and reuse accumulated } \\
\text { knowledge, make decisions and monitor their } \\
\text { implementation. It should be borne in mind that } \\
\text { effective coordination requires constant professional } \\
\text { development and the development of expert and } \\
\text { leadership motivation of the participant }\end{array}$ \\
\hline $\begin{array}{l}\text { The growing } \\
\text { complexity } \\
\text { of models } \\
\text { outstripping } \\
\text { the growth } \\
\text { of intelligence }\end{array}$ & $\begin{array}{l}\text { Working with big data leads to the emergence of a wide } \\
\text { variety of operating models, as well as to the complication } \\
\text { of cause-and-effect relationships in these models. Using } \\
\text { these models to make decisions will require a lot of } \\
\text { intellectual resources. If the growth of intelligence will } \\
\text { constantly lag behind the growth of the complexity of models, } \\
\text { then decision-making will be constantly accompanied by } \\
\text { errors, their corrections and additional changes }\end{array}$ & $\begin{array}{l}\text { The constant increase in the complexity and } \\
\text { diversity of activity models will stimulate the } \\
\text { development of our intellectual abilities, as it } \\
\text { has always been in history. }\end{array}$ \\
\hline $\begin{array}{l}\text { Increasing } \\
\text { the speed } \\
\text { of processes } \\
\text { and their } \\
\text { individualization }\end{array}$ & $\begin{array}{l}\text { Digitalization allows you to radically increase the } \\
\text { productivity of operational processes, reaching the level } \\
\text { of value chains that go beyond the boundaries of the } \\
\text { organization. At the same time, the implementation of } \\
\text { each order in the process becomes more and more } \\
\text { individual. This leads to the fact that the speed of } \\
\text { implementing changes increases and the implementation } \\
\text { of changes itself becomes more complex and diverse }\end{array}$ & $\begin{array}{l}\text { Some of the decisions at the lower level, } \\
\text { especially in the conditions of increasing speed } \\
\text { and individualization of processes, will be taken } \\
\text { over by artificial intelligence systems. } \\
\text { Decision-making at the higher levels in the context } \\
\text { of increasing speed and diversity will remain up } \\
\text { to the individual. New thinking "in complexity" } \\
\text { can reduce the impact of these changes }\end{array}$ \\
\hline
\end{tabular}


At each moment of time, complete and reliable information is provided about the current status of the MTR supply request and their movement, which serves as feedback for the process control loops. Based on this information, management decision-making systems work, many of which are implemented using artificial intelligence.

Thus, from the point of view of the execution of each specific application for MTR, the system behaves in a completely unpredictable way, making operational decisions at any stage. For example, if a delivery delay is detected under a framework contract, the system can automatically generate purchase orders from a retail network. When the previous production stage required less MTP than planned, changes are made throughout the supply chain. The smartest systems can take other factors into account. For example, a decrease in ambient air temperature will lead to an increase in electricity consumption for boiler houses and additional material consumption for maintenance and repair of equipment that is serviced on time. Thus, the statistical sustainability mode is implemented, when the instability of each instance of the process makes it possible to implement a stable provision for the production of MTR. Controlling this process is more like the stability/instability of a fighter plane than the stability of a transport plane.

We see that the planning and execution of MTP applications is becoming more individual and less predictable, that is, there is an increase in diversity in the flow of MTP applications (LS-mode). The planning system manages not only to rapidly execute a new application and, if necessary, quickly adjust plans to already running applications, that is, dispels a variety of flow applications (HS-mode). This MTP planning system ensures the parity of growth and dispersion of the diversity of the application flow and makes it statistically stable. Interestingly, it is in this mode of statistical sustainability that elements of self-organization begin to manifest themselves: the system begins to "suggest" new possible planning methods that are specific to this business and are very different from the widely used MRP II models.

The existence of a regime of statistical sustainability of a digital organization is not a problem, but an objective property that it is pointless to fight. Statistical sustainability has to be learned to live with, and it looks like it could become the new norm for digital organizations.

The study of the nature of exponential organizations [1] clearly shows that their explosive growth is always accompanied by an increase in variability, which constantly brings them to the edge of the stability of their business. Exponential organizations have learned to live in a statistical sustainability mode that allows them to balance on the edge of sustainability and maintain a high level of innovation in their business. It is in the mode of statistical sustainability, through trial and error, that these companies have managed to find the sources of their explosive growth. Interestingly, exponential organizations consciously maintain a statistical sustainability regime even as they transform from startups to large companies. Even when exponential organizations stabilize their individual operational business processes, they still maintain a high readiness to transition to statistical sustainability and readiness for change.

\section{Conclusion}

Systematic digitalization puts an organization in a state of statistical sustainability, when the predictability of the actions of its individual participants begins to disappear, but the predictability as a whole still persists. From the point of view of traditional management, focused on long - term predictability and classical stability of the forms of organization, statistical sustainability is a chaos and a source of risks that must be dealt with. From the point of view of the management of digital organi- 
zations, focused on a high level of variability and rapid growth, statistical sustainability is a generator of new practices and a source of new opportunities. In this mode, the organization can balance on the edge of sustainability and maintain a high level of variability and innovation.

Digitalization is often perceived as a traditional reengineering of business processes, but only on the basis of new technologies. In this case, statistical sustainability is traditionally considered as a source of risks and they begin to fight it. In fact, statistical sustainability is a necessary condition for both the transformation into a digital organization and its further life activity, so it must be stimulated and supported.

Digitalization encourages the development of the instability of the organization, and it pushes it to the edge of a cliff. But it is here, on the edge of the cliff, that its new nature is revealed: it turns out that the organization is not a machine, but an organism to which management will have to adapt. If nature is for us, who is against us? Woe to those who struggle with nature.

\section{References}

1. Ismail S., Malone M.S., van Geest Y. (2014) Exponential organizations: Why new organizations are ten times better, faster, and cheaper than yours (and what to do about it). Diversion Books.

2. Schwab K. (2017) The fourth industrial revolution. London: Penguin Books.

3. Agamirzyan I.R., et. al (2016) Challenge 2035. Moscow: Olymp Business (in Russian).

4. PwC (2016) Industry 4.0: Building the digital enterprise. 2016 Global Industry 4.0 Survey. Available at: https://www.pwc.com/gx/en/industries/industries-4.0/landing-page/industry-4.0-building-your-digitalenterprise-april-2016.pdf (accessed 15 October 2020).

5. The Government of the Russian Federation (2017) The program "Digital economy of the Russian Federation. ”Approved by Order of the Government of the Russian Federation No 1632-r of 28 July 2017. Available at: http://static.government.ru/media/files/9gFM4FHj4PsB79I5v7yLVuPgu4bvR7M0.pdf (accessed 15 December 2020) (in Russian).

6. Ananyin V.I., Zimin K.V., Lugachev M.I, Gimranov R.D., Skriprin K.G. (2018) Digital organization: Transformation into the new reality. Business Informatics, no. 2, pp. 45-54. DOI: $10.17323 / 1998-0663.2018 .2 .45 .54$.

7. Ananyin V.I., Zimin K.V., Gimranov R.D., Lugachev M.I, Skriprin K.G. (2019) Real time enterprise management in the digitalization era. Business Informatics, vol. 13, no 1, pp. 7-17.

DOI: 10.17323/1998-0663.2019.1.7.17.

8. Taleb N.N. (2007) The black swan: The impact of the highly improbable. New York: Random House.

9. Korotkov E.M. (2003) Anti-crisis management. Moscow: INFRA-M (in Russian).

10. Sheremet A.D., Negashev E.V. (2016) Methodology of financial analysis of commercial organizations' activities. Moscow: INFRA-M (in Russian).

11. The Russian Federation (1994) Federal Law of the Russian Federation No 68-FZ of 21 December 1994 "On the protection of the population and territories from natural and man-made emergencies." Available at: http://www.consultant.ru/document/cons_doc_LAW_5295/(accessed 15 December 2020) (in Russian).

12. Gaponenko A.L., Savelieva M.V. (2020) Theory of management. Moscow: Urait (in Russian).

13. Prigogine I., Stengers I. (1984) Order out of chaos: Man's new dialogue with nature. Bantam New Age Books.

14. Haken H. (2006) Information and self-organization: A macroscopic approach to complex systems. Berlin, Heidelberg: Springer. 
15. Kurdyumov S.P., Malinetsky G.G., Potapov A.B. (1989) Synergetics - new directions. Moscow: Znanie (in Russian).

16. Malinetsky G.G. (2017) Mathematical foundations of synergetics: Chaos, structures, computational experiment. Moscow: URSS (in Russian).

17. Maturana H.R., Varela F.J. (1980) Autopoiesis and cognition: The realization of the living. Dordrecht: D. Reidel Publishing.

18. Vasilkova V.V. (1999) Order and chaos in the development of social systems: Synergetics and theory of social self-organization. St. Petersburg: Lan' (in Russian).

19. Kershengolts B.M., Chernobrovkina T.V., Shein A.A., Khlebhy E.S., Anshakova V.V. (2009) Nonlinear dynamics (synergetics) in chemical, biological, and biotechnological systems. Yakutsk: Ammosov Yakut State University (in Russian).

\section{About the authors}

\section{Vladimir I. Ananyin}

Senior Lecturer, Department on Business Processes Management, Russian Presidential Academy of National Economy and Public Administration, 82 build.1, Prospect Vernadskogo, Moscow 119571, Russia;

E-mail: v.ananiin@gmail.com

\section{Konstantin V. Zimin}

Editor-in-Chief, Information Management Journal;

Member of the Board, The Russian Union of CIO, 34, Seleznevskaya Street, Moscow 123056, Russia;

E-mail: konst.zimin@gmail.com

\section{Mikhail I. Lugachev}

Dr. Sci. (Econ.), Professor;

Academic Supervisor of Department of Economic Informatics, Lomonosov Moscow State University, 1 build. 46, GSP-1, Leninskie Gory, Moscow 119991, Russia;

E-mail: mlugachev@gmail.com

ORCID: 0000-0002-6871-3328

\section{Rinat D. Gimranov}

Head of IT Department, PJSC Surgutneftegaz, 1 block 1, Grigoriya Kukuevitskogo Street, Surgut 628415, Russia;

E-mail: gimranov_rd@mail.ru 